\title{
Establishing Expert, Multi-Disciplinary, Peer- Reviewed Consensus to Lead a Paradigm Shift in Optimal Blood Glucose Management
}

\author{
Douglas A. Robertson • Richard A. Chudleigh • Simon D. Gwynn • \\ Carol Jairam · Kaushal Kansagra • Naresh Kanumilli · Adam Lester-George • \\ Charlotte McMurray · Timothy C. Warren
}

Received: January 24, 2019 / Published online: March 19, 2019

(C) The Author(s) 2019

\section{ABSTRACT}

Introduction: The National Health Service (NHS) in the UK appears unclear on how blood glucose monitoring (BGM) should be used to support diabetes patient care and empowerment, and local interpretation of NICE guidance on the availability of devices varies widely. An expert group of clinicians and

Enhanced Digital Features To view enhanced digital features for this article go to https://doi.org/10.6084/ m9.figshare.7819586.

D. A. Robertson $(\bowtie)$

Leighton Hospital, Crewe, UK

e-mail: doug.robertson@nhs.net

R. A. Chudleigh

Singleton Hospital, Swansea, UK

S. D. Gwynn · T. C. Warren

Triducive Ltd., Tunbridge Wells, UK

C. Jairam

Imperial College, London, UK

K. Kansagra

Shotfield Medical Practice, Wallington, UK

N. Kanumilli

Northenden Group Practice, Manchester, UK

\section{A. Lester-George}

LeLan Ltd, Bristol, UK

C. McMurray

Sheffield Clinical Commissioning Group, Sheffield, UK commissioners considered BGM in terms of access, guidance, resources, data integration, patient education, and patient choice.

Methods: The group generated a series of questions on BGM into a 38-statement questionnaire using Delphi methodology. This was circulated to clinicians involved in diabetes management across the UK, receiving 222 responses.

Results: From the questionnaire, 35 of the 38 statement responses showed $>66 \%$ consensus, with 26 of these achieving $>90 \%$ agreement.

Conclusion: The expert group reviewed the responses and made recommendations based on the clear professional consensus demonstrated. These included the need to use new technology and data integration and that wider factors, including patient choice rather than cost alone, should inform formulary inclusion of BGM equipment.

Funding: LifeScan U.K. Ltd.

Keywords: BGM; Blood glucose; Glycemic control; Consensus; Monitoring; Type 1 diabetes; Type 2 diabetes

\section{INTRODUCTION}

Diabetes is a widely prevalent long-term condition in which raised blood glucose levels over time contribute to complications that are costly in terms of healthcare use and impact adversely 
on quality of life. Blood glucose monitoring (BGM) has an important part to play in the management of blood glucose in diabetes and the reduction of risk of serious secondary complications [1]. The first BGM meter was introduced in 1970 [1], and available technology has evolved markedly since then. In today's technology-rich environment, self-monitoring of blood glucose is an integral part of effective diabetes management [2], allowing patients to monitor their glycemic status and adjust their therapy accordingly.

Modern healthcare requires that long-term conditions are managed in a shared and collaborative way between the patient and all stakeholders involved in their care, rather than solely by the patient or healthcare professionals (HCPs). Despite clear demonstrations of the benefits of BGM meters that provide feedback to patients [2], and diabetes being almost universally managed in the UK by NHS professionals, there is an apparent lack of clarity within the NHS regarding emerging BGM technologies and their potential to positively impact service delivery and increase resource efficiency while supporting patient empowerment. This was demonstrated in a survey of over 1000 BGM users carried out by Diabetes UK [3], with the responses suggesting that NICE (National Institute for Health and Care Excellence) guidance is not always implemented as recommended for type 1 [4] and type 2 [5] diabetes.

This consensus steering group (all members are co-authors to this paper) has sought the real-life perspectives of NHS staff involved in diabetes care to gain an understanding of their attitudes to BGM technology and its value for people with diabetes who require intensive BG monitoring. This was felt necessary because the speed of introduction of technology was perceived to move more quickly even than centralized expert guidance. In order to fulfil the requirements for fully collaborative shared care, it is important that optimum technology is utilized and a 'big data' approach is adopted, in order to increase resource efficiency.

\section{METHODS}

This article does not contain any studies with human participants or animals performed by any of the authors.

The group used the Delphi [6] methodology to validate the views of a large number of peers regarding BGM in the current UK National Health Service (NHS) setting, with the goal of better understanding their views regarding changing demographics and BGM technology. The recommendations derived from the responses seek to support HCPs in assessing new technologies available to them and provide decision-support for choice of technology. As such, these consensus views and recommendations which the group felt were justifiable from the responses are offered in order to provide a reference point for the use of BGM for both commissioners and providers. In addition, the consensus process aimed to identify regional variation in the responses to statements and is intended to inform the paradigm shift required to adopt new technologies for BGM.

A group of clinicians and payers involved in diabetes care met to review the current adoption of BGM systems in the UK and determine a framework for consensus. Seven key topics were initially identified, and consensus statements developed for each (Table 1). These statements were collated into a questionnaire, which was circulated widely over a 3-month period to clinicians involved in diabetes management by in-person cascade and by e-mail from group members and with the help of LifeScan, Inc. (London, UK) representatives. Responses were collated and analyzed in confidence by Triducive Ltd (St Albans, UK). Respondents were required to use a 4-point Likert scale to rate their agreement with each statement. Responses were: 'strongly disagree'; 'tend to disagree'; 'tend to agree'; and 'strongly agree.' The questionnaire also asked respondents for their locality, their speciality, and the department in which they work. While personal details were not used for reporting results, clinical background and locality were used to assess potential differences in responses between professions and across the UK. 


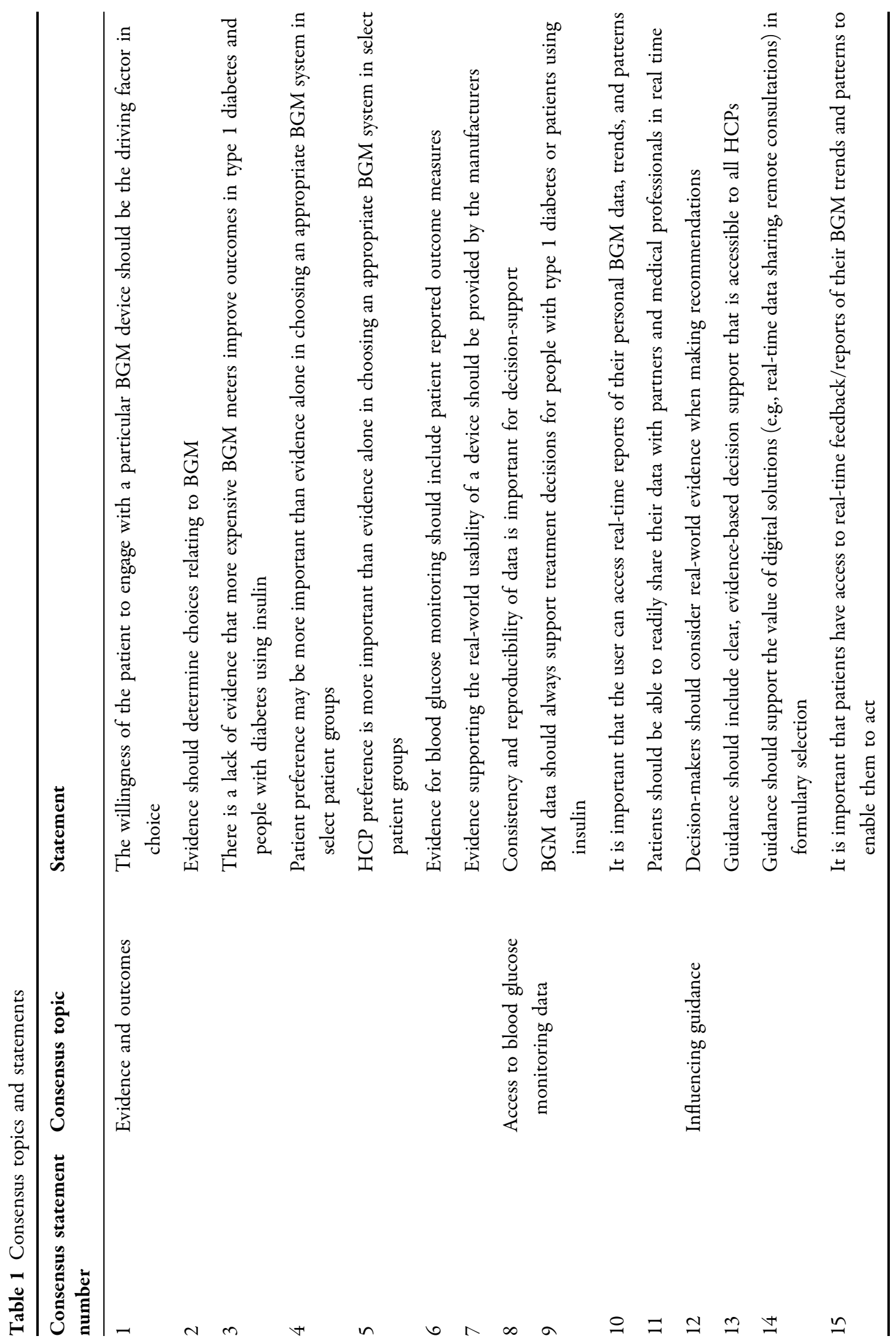




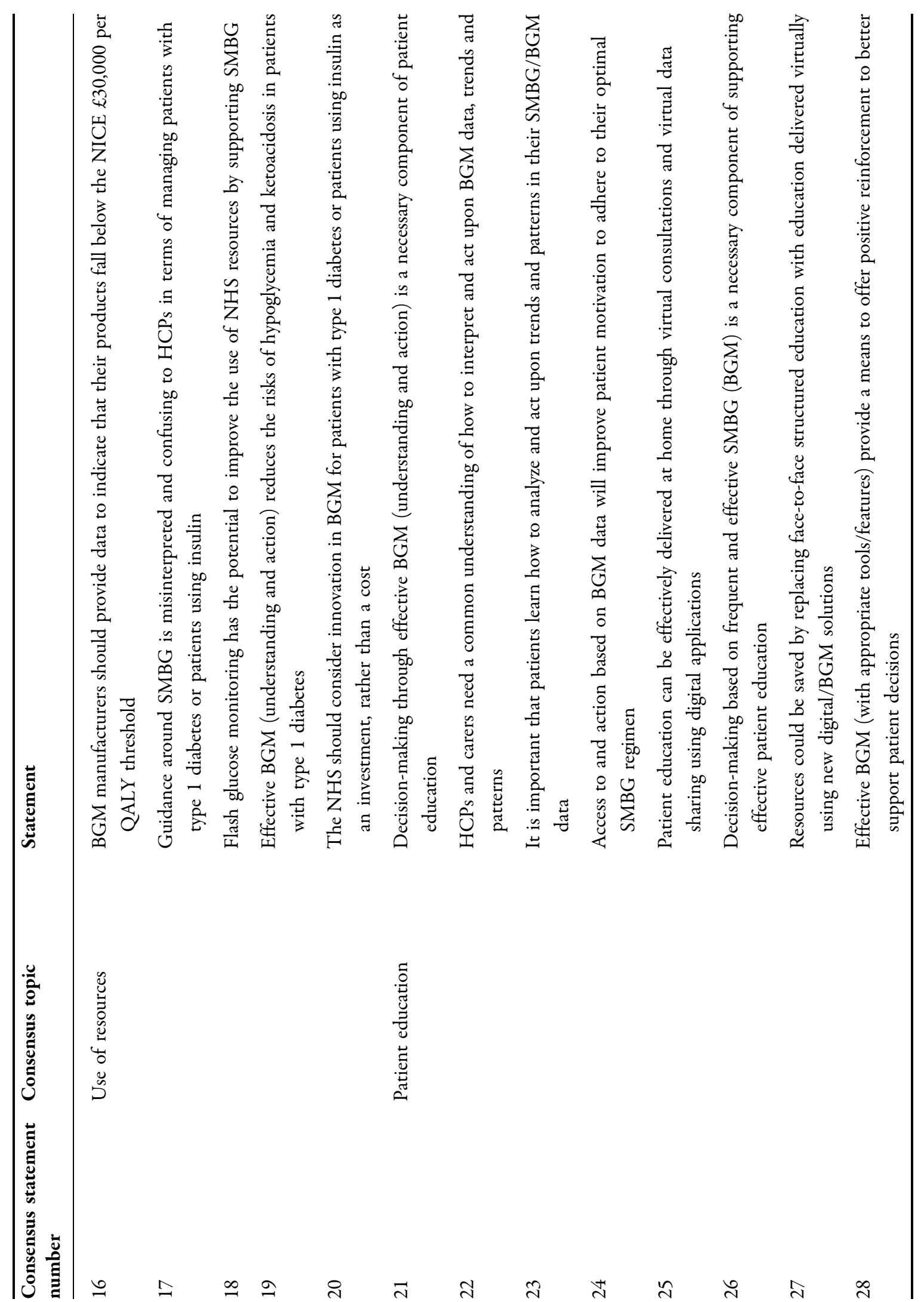




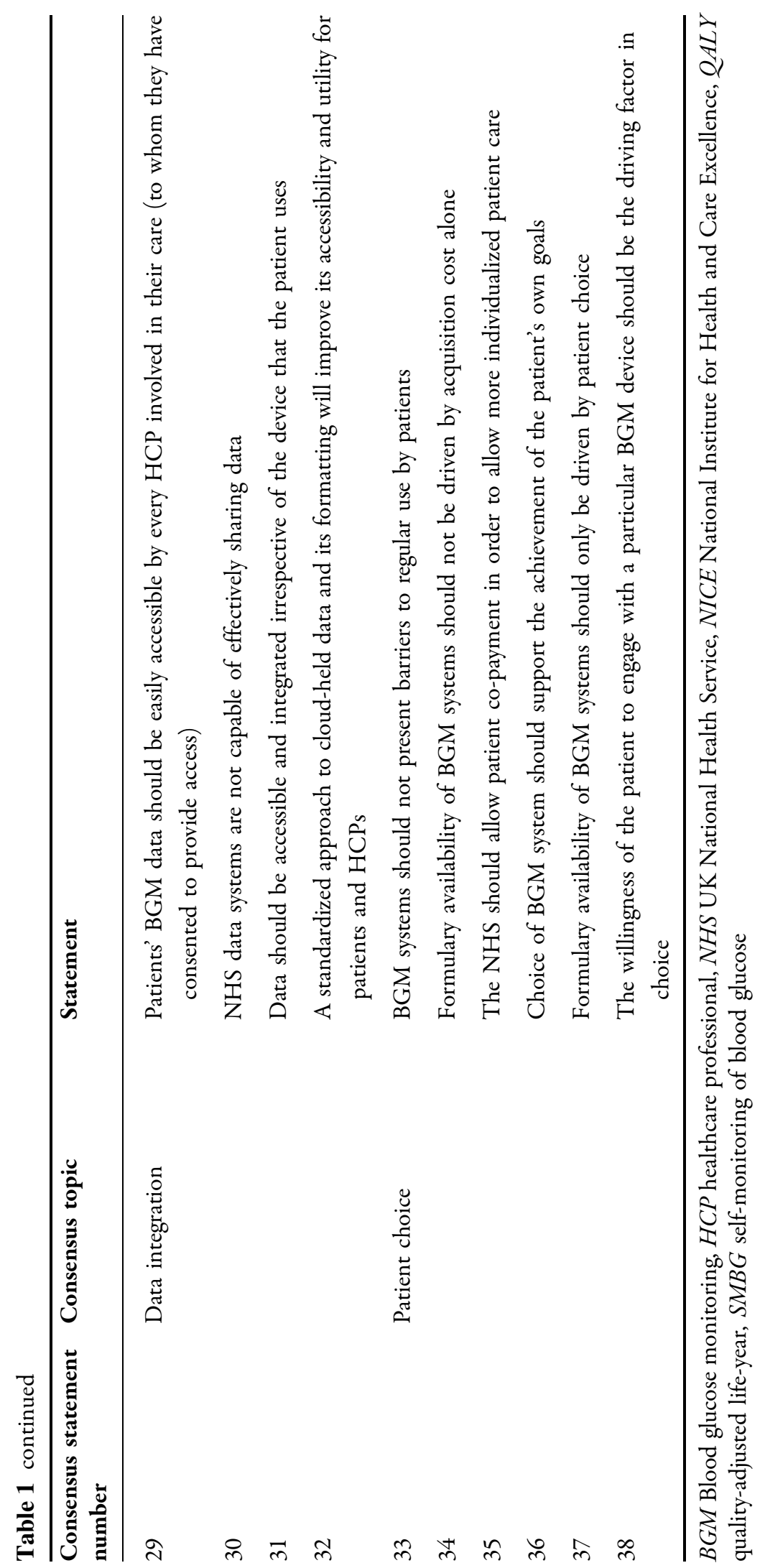


Completed questionnaires were then collated, and the individual scores for each statement analyzed in order to produce a full arithmetic agreement score for each statement. The responses were then sub-grouped by locality and specialty to identify variances in the respondent's agreement scores by either geography or role.

The steering group had predefined the threshold of agreement for consensus at $\geq 66 \%$. Consensus was defined as 'high' at $\geq 66 \%$ and 'very high' at $\geq 90 \%$.

Due to the high levels of agreement with all but three of the statements, demonstrating very strong consensus views, the group elected to avoid a further round of questionnaires to generate a larger number of responses, and instead chose to work with the responses to the original statements.

\section{RESULTS}

Completed questionnaires were returned by 222 respondents. The questionnaires were analyzed to score the total level of agreement with each of the 38 statements. Of the 38 statements, 35 (92\%) achieved an agreement score exceeding the $66 \%$ threshold, and 26 of these (68\%) exceeded 90\% agreement (Table 2, Fig. 1).

Only three of the statements achieved an agreement score of $<66 \%$ or $>33 \%$ and thus were defined as not achieving consensus (Table 3).

Respondents were analyzed by region. The number of respondents from each region is shown in Table 4 . The sample was dominated by respondents from England $(n=136)$ while only four respondents were from Wales. Eighteen respondents did not indicate their region.

While the majority of statements were scored similarly, irrespective of the respondent's region (Fig. 2), nine statements showed larger regional variation in score (Table 5).

Responses were also analyzed according to the respondent's role (Table 6).

While the largest single respondent groups by role were diabetologists and diabetes specialist nurses (DSNs), 39 respondents did not share their role on the questionnaire and thus remain unknown and 19 had other roles. Comparison between the responses of diabetologists, DSNs and the group overall is shown in Fig. 3.

With the exception of statements $3,4,5,16$, $17,27,30$, and 37 , the views of DSNs were well aligned with those of the wider group. The variation in agreement scores for these statements according to role is shown in Table 7.

\section{DISCUSSION}

In this paper we describe the consensus views of a large group of clinicians working the UK NHS, a government-funded, cost-limited healthcare system that is substantially free at the point of use. As such, the recommendations and views presented here may not reflect the views of HCPs in other healthcare systems.

For patients with a need to optimize their glycemic control, many factors may influence their choice of BGM system. Understanding the value of a system to a patient may be a more important measure than simply looking at the acquisition cost of that device. In light of this, sharing the acquisition cost with the patient may be a valid option, as patients have demonstrated that when a device is recognized as offering important advantages, they may be willing to contribute to the cost [7].

Effective BGM is recognized by $99.1 \%$ of respondents as having the potential to reduce hypoglycemia and ketoacidosis in patients with type 1 diabetes. Effective BGM may be regarded as achieving tight glycemic control (according to the type of diabetes) in line with personalized goals.

Respondents strongly agree with the assertion that flash glucose monitoring has the potential to improve the use of NHS resources (88.9\% agreement) and should be considered as an investment rather than a cost $(96.3 \%$ agreement).

\section{Influencing Guidance}

Unsurprisingly, respondents strongly agree with statements 12 and 13 concerning the need for real-world evidence when making 
Table 2 Consensus statements and agreement scores

\begin{tabular}{|c|c|c|c|}
\hline $\begin{array}{l}\text { Consensus } \\
\text { statement } \\
\text { number }\end{array}$ & Topic & Statement & $\begin{array}{l}\text { Agreement } \\
\text { score }(\%)\end{array}$ \\
\hline 1 & \multirow[t]{7}{*}{$\begin{array}{l}\text { Evidence and } \\
\text { outcomes }\end{array}$} & $\begin{array}{l}\text { The willingness of the patient to engage with a particular BGM } \\
\text { device should be the driving factor in choice }\end{array}$ & 93.7 \\
\hline 2 & & $\begin{array}{l}\text { Evidence should determine choices relating to blood glucose } \\
\text { monitoring }\end{array}$ & 92.7 \\
\hline 3 & & $\begin{array}{l}\text { There is a lack of evidence that more expensive BGM meters } \\
\text { improve outcomes in type } 1 \text { diabetes and people with diabetes } \\
\text { using insulin }\end{array}$ & 78.5 \\
\hline 4 & & $\begin{array}{l}\text { Patient preference may be more important than evidence alone in } \\
\text { choosing an appropriate BGM system in select patient groups }\end{array}$ & 71.8 \\
\hline 5 & & $\begin{array}{l}\text { HCP preference is more important than evidence alone in } \\
\text { choosing an appropriate BGM system in select patient groups }\end{array}$ & 34.9 \\
\hline 6 & & $\begin{array}{l}\text { Evidence for blood glucose monitoring should include patient } \\
\text { reported outcome measures }\end{array}$ & 97.2 \\
\hline 7 & & $\begin{array}{l}\text { Evidence supporting the real-world usability of a device should be } \\
\text { provided by the manufacturers }\end{array}$ & 95.0 \\
\hline 8 & \multirow{4}{*}{$\begin{array}{l}\text { Access to blood } \\
\text { glucose monitoring } \\
\text { data }\end{array}$} & $\begin{array}{l}\text { Consistency and reproducibility of data is important for decision } \\
\text { support }\end{array}$ & 99.1 \\
\hline 9 & & $\begin{array}{l}\text { BGM data should always support treatment decisions for people } \\
\text { with type } 1 \text { diabetes or patients using insulin }\end{array}$ & 98.2 \\
\hline 10 & & $\begin{array}{l}\text { It is important that the user can access real time reports of their } \\
\text { personal BGM data, trends and patterns }\end{array}$ & 94.5 \\
\hline 11 & & $\begin{array}{l}\text { Patients should be able to readily share their data with partners } \\
\text { and medical professionals in real time }\end{array}$ & 96.8 \\
\hline 12 & \multirow[t]{4}{*}{ Influencing guidance } & $\begin{array}{l}\text { Decision-makers should consider real world evidence when } \\
\text { making recommendations }\end{array}$ & 98.6 \\
\hline 13 & & $\begin{array}{l}\text { Guidance should include clear, evidence-based decision support } \\
\text { that is accessible to all HCPs }\end{array}$ & 97.7 \\
\hline 14 & & $\begin{array}{l}\text { Guidance should support the value of digital solutions (e.g. real } \\
\text { time data sharing, remote consultations) in formulary selection }\end{array}$ & 98.2 \\
\hline 15 & & $\begin{array}{l}\text { It is important that patients have access to real time feedback/ } \\
\text { reports of their BGM trends and patterns to enable them to } \\
\text { take action }\end{array}$ & 96.8 \\
\hline
\end{tabular}


Table 2 continued

\begin{tabular}{|c|c|c|c|}
\hline $\begin{array}{l}\text { Consensus } \\
\text { statement } \\
\text { number }\end{array}$ & Topic & Statement & $\begin{array}{l}\text { Agreement } \\
\text { score (\%) }\end{array}$ \\
\hline
\end{tabular}

16 Use of resources BGM manufacturers should provide data to indicate that their

17

18

19 products fall below the NICE $£ 30,000$ per QALY threshold

Guidance around SMBG is misinterpreted and confusing to HCPS in terms of managing patients with type 1 diabetes or patients using insulin

Flash glucose monitoring has the potential to improve the use of NHS resources by supporting SMBG

Effective BGM (understanding and action) reduces the risks of hypoglycemia and ketoacidosis in patients with type 1 diabetes

The NHS should consider innovation in BGM for patients with type 1 diabetes or patients using insulin as an investment, rather than a cost

Patient education

Decision making through effective BGM (understanding and action) is a necessary component of patient education

HCPs and carers need a common understanding of how to interpret and act upon BGM data, trends and patterns

It is important that patients learn how to analyze and act upon trends and patterns in their SMBG/BGM data

Access to and action based on BGM data will improve patient motivation to adhere to their optimal SMBG regimen

Patient education can be effectively delivered at home through virtual consultations and virtual data sharing using digital applications

Decision making based on frequent and effective SMBG (BGM) is a necessary component of supporting effective patient education

Resources could be saved by replacing face-to-face structured education with education delivered virtually using new digital/ BGM solutions

Effective BGMs (with appropriate tools/features) provide a means to offer positive reinforcement to better support patient decisions 
Table 2 continued

\begin{tabular}{|c|c|c|c|}
\hline $\begin{array}{l}\text { Consensus } \\
\text { statement } \\
\text { number }\end{array}$ & Topic & Statement & $\begin{array}{l}\text { Agreement } \\
\text { score }(\%)\end{array}$ \\
\hline 29 & Data integration & $\begin{array}{l}\text { Patients' BGM data should be easily accessible by every HCP } \\
\text { involved in their care (to whom they have consented to provide } \\
\text { access) }\end{array}$ & 98.6 \\
\hline 30 & & NHS data systems are not capable of sharing data effectively & 81.0 \\
\hline 31 & & $\begin{array}{l}\text { Data should be accessible and integrated irrespective of the device } \\
\text { that the patient uses }\end{array}$ & 97.2 \\
\hline 32 & & $\begin{array}{l}\text { A standardized approach to cloud-held data and its formatting } \\
\text { will improve its accessibility and utility for patients and HCPs }\end{array}$ & 98.1 \\
\hline 33 & Patient choice & $\begin{array}{l}\text { BGM systems should not present barriers to regular use by } \\
\text { patients }\end{array}$ & 100.0 \\
\hline 34 & & $\begin{array}{l}\text { Formulary availability of BGM systems should not be driven by } \\
\text { acquisition cost alone }\end{array}$ & 92.2 \\
\hline 35 & & $\begin{array}{l}\text { The NHS should allow patient co-payment in order to allow } \\
\text { more individualised patient care }\end{array}$ & 77.0 \\
\hline 36 & & $\begin{array}{l}\text { Choice of BGM system should support the achievement of the } \\
\text { patient's own goals }\end{array}$ & 98.2 \\
\hline 37 & & $\begin{array}{l}\text { Formulary availability of BGM systems should only be driven by } \\
\text { patient choice }\end{array}$ & 44.7 \\
\hline 38 & & $\begin{array}{l}\text { The willingness of the patient to engage with a particular BGM } \\
\text { device should be the driving factor in choice }\end{array}$ & 84.3 \\
\hline
\end{tabular}

Total Consensus Agreement Scores

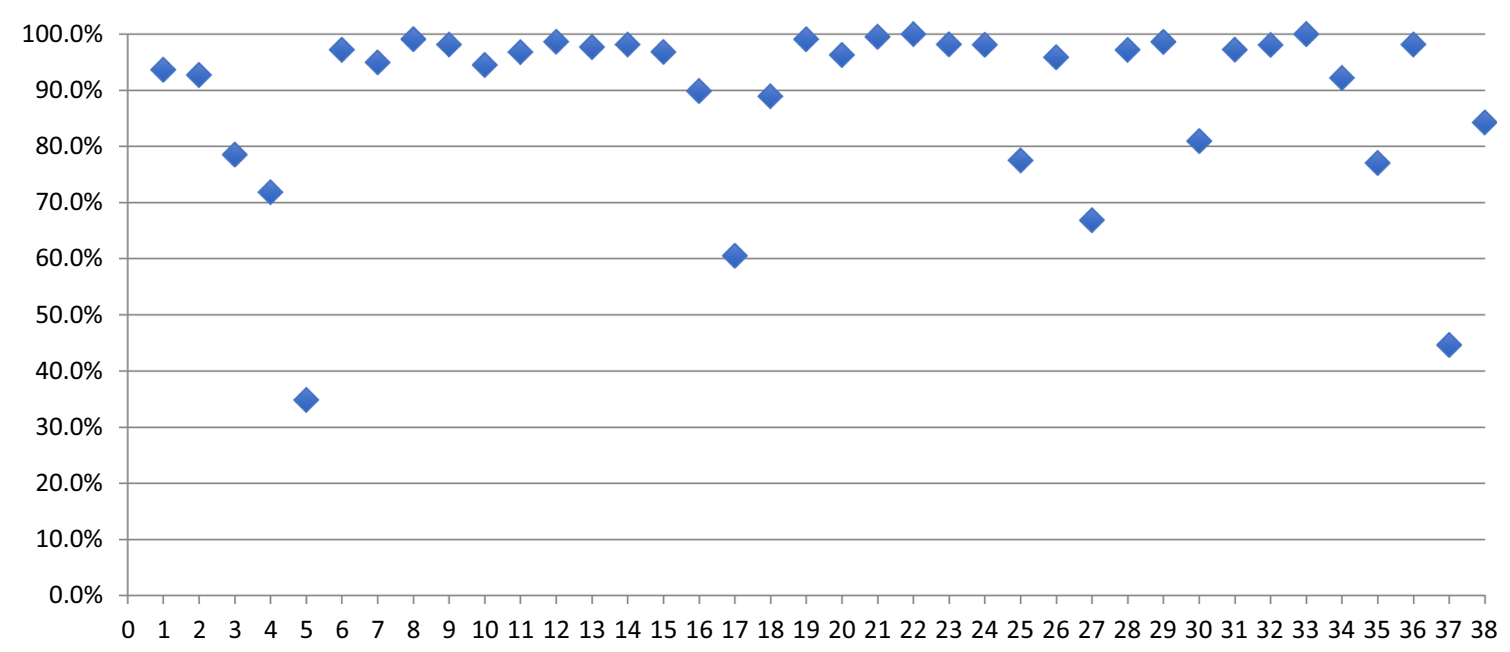

Fig. 1 Plot of total consensus agreement scores 
Table 3 Statements with agreement scores of between 33 and 66\%

\begin{tabular}{llll}
\hline $\begin{array}{l}\text { Consensus } \\
\text { statement } \\
\text { number }\end{array}$ & Topic & Statement & $\begin{array}{c}\text { Agreement } \\
\text { score (\%) }\end{array}$ \\
\hline 5 & $\begin{array}{c}\text { Evidence and } \\
\text { outcomes }\end{array}$ & $\begin{array}{c}\text { HCP preference is more important than evidence alone in choosing an } \\
\text { appropriate BGM system in select patient groups }\end{array}$ & 34.9 \\
17 & $\begin{array}{c}\text { Use of } \\
\text { resources }\end{array}$ & $\begin{array}{c}\text { Guidance around SMBG is misinterpreted and confusing to HCPS in } \\
\text { terms of managing patients with type 1 diabetes or patients using } \\
\text { insulin }\end{array}$ \\
& $\begin{array}{c}\text { Patient } \\
\text { choice }\end{array}$ & $\begin{array}{c}\text { Formulary availability of BGM systems should only be driven by patient } \\
\text { choice }\end{array}$ & 44.7 \\
\hline
\end{tabular}

Table 4 Respondents by region

\begin{tabular}{lc}
\hline Region & Number of respondents \\
\hline England & 136 \\
Scotland & 26 \\
Wales & 4 \\
Northern Ireland & 18 \\
London & 13 \\
Unknown & 25 \\
Total & 222 \\
\hline
\end{tabular}

recommendations and the need for clarity in the evidence base from guidance used in decision-support. There is strong agreement $(98.2 \%)$ endorsing the need for digital solutions, which may support the objective of increasing personal management of long-term conditions. In addition, $96.8 \%$ of respondents agree that patients should have access to real-time data enabling them to act.

In total, $98.2 \%$ of delegates support the view that guidance should support the value of digital solutions when it comes to formulary inclusion. However, BGM formulary decisions are still firmly focused on devices and the acquisition cost of the device test strips, despite the NHS's intention to move to solutions that are orientated around digital, big data and evidence that demonstrates an impact on health outcomes.

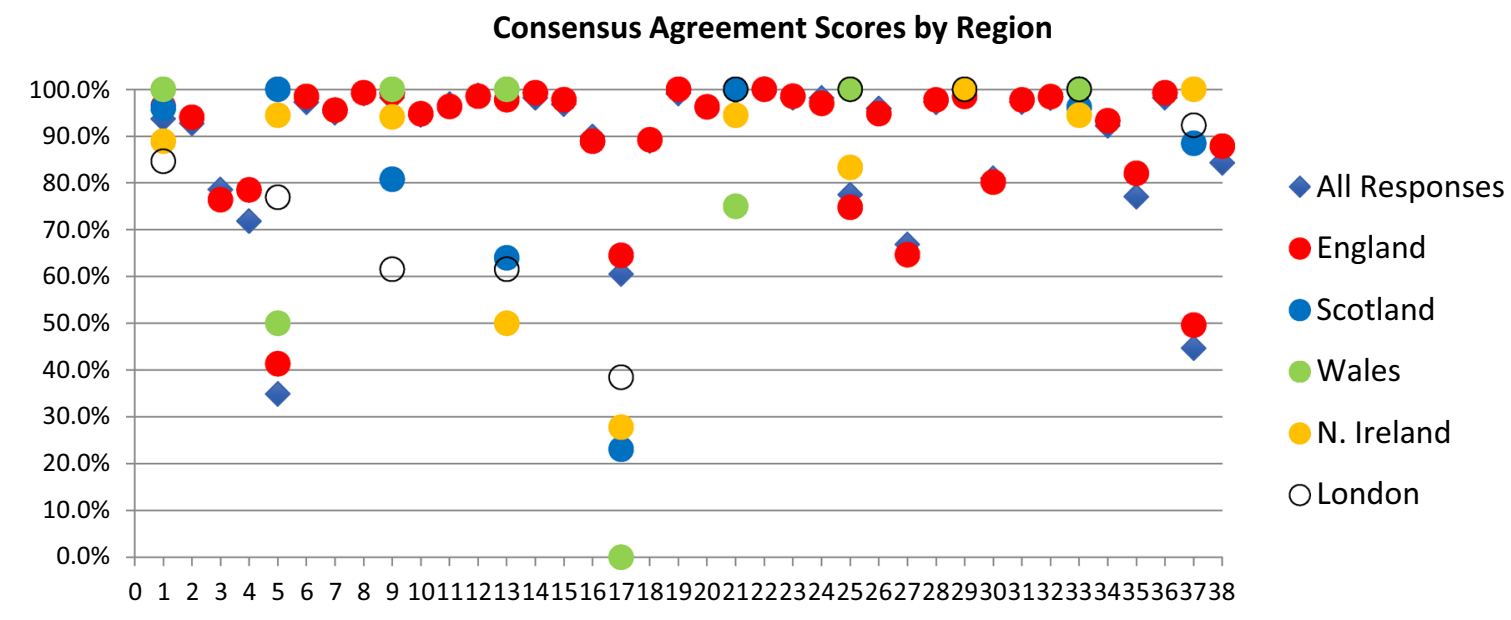

Fig. 2 Consensus agreement scores by region 
Table 5 Statements with largest regional variation in agreement scores

\begin{tabular}{|c|c|c|c|c|c|c|c|}
\hline \multirow{2}{*}{$\begin{array}{l}\text { Consensus } \\
\text { statement } \\
\text { number }\end{array}$} & \multirow[t]{2}{*}{ Topic } & \multirow[t]{2}{*}{ Statement } & \multicolumn{5}{|c|}{ Agreement scores (\%) } \\
\hline & & & $\begin{array}{l}\text { England } \\
(\%)\end{array}$ & $\begin{array}{l}\text { Scotland } \\
(\%)\end{array}$ & $\begin{array}{l}\text { Wales } \\
(\%)\end{array}$ & $\begin{array}{l}\text { Northern } \\
\text { Ireland } \\
(\%)\end{array}$ & $\begin{array}{l}\text { London } \\
(\%)\end{array}$ \\
\hline 2 & \multirow{4}{*}{$\begin{array}{l}\text { Evidence } \\
\text { and } \\
\text { outcomes }\end{array}$} & $\begin{array}{l}\text { Evidence should determine choices } \\
\text { relating to BGM }\end{array}$ & 94.0 & 100.0 & 50.0 & 94.4 & 76.9 \\
\hline 3 & & $\begin{array}{l}\text { There is a lack of evidence that } \\
\text { more expensive BGM meters } \\
\text { improve outcomes in type } 1 \\
\text { diabetes and people with diabetes } \\
\text { using insulin }\end{array}$ & 76.4 & 80.8 & 100.0 & 94.1 & 61.5 \\
\hline 4 & & $\begin{array}{l}\text { Patient preference may be more } \\
\text { important than evidence alone in } \\
\text { choosing an appropriate BGM } \\
\text { system in select patient groups }\end{array}$ & 78.5 & 64.0 & 100.0 & 50.0 & 61.5 \\
\hline 5 & & $\begin{array}{l}\text { HCP preference is more important } \\
\text { than evidence alone in choosing } \\
\text { an appropriate BGM system in } \\
\text { select patient groups }\end{array}$ & 41.4 & 23.1 & 0.0 & 27.8 & 38.5 \\
\hline 16 & \multirow[t]{2}{*}{$\begin{array}{l}\text { Use of } \\
\text { resources }\end{array}$} & $\begin{array}{l}\text { BGM manufacturers should provide } \\
\text { data to indicate that their } \\
\text { products fall below the NICE } \\
£ 30,000 \text { per QALY threshold }\end{array}$ & 88.9 & 92.3 & 75.0 & 100.0 & 84.6 \\
\hline 17 & & $\begin{array}{l}\text { Guidance around SMBG is } \\
\text { misinterpreted and confusing to } \\
\text { HCPS in terms of managing } \\
\text { patients with type } 1 \text { diabetes or } \\
\text { patients using insulin }\end{array}$ & 64.5 & 61.5 & 25.0 & 42.9 & 46.2 \\
\hline 25 & $\begin{array}{l}\text { Patient } \\
\text { education }\end{array}$ & $\begin{array}{l}\text { Patient education can be effectively } \\
\text { delivered at home through virtual } \\
\text { consultations and virtual data } \\
\text { sharing using digital applications }\end{array}$ & 74.8 & 73.1 & 100 & 76.5 & 76.9 \\
\hline 35 & \multirow[t]{2}{*}{$\begin{array}{l}\text { Patient } \\
\text { choice }\end{array}$} & $\begin{array}{l}\text { The NHS should allow patient co- } \\
\text { payment in order to allow more } \\
\text { individualised patient care }\end{array}$ & 82.0 & 65.4 & 50.0 & 72.2 & 75.0 \\
\hline 38 & & $\begin{array}{l}\text { The willingness of the patient to } \\
\text { engage with a particular BGM } \\
\text { device should be the driving factor } \\
\text { in choice }\end{array}$ & 87.9 & 84.6 & 100.0 & 70.6 & 38.5 \\
\hline
\end{tabular}


Table 6 Respondents by role

\begin{tabular}{lc}
\hline Role & $\boldsymbol{N}$ \\
\hline Diabetologist & 53 \\
Diabetes specialist nurse & 45 \\
Pharmacist & 22 \\
Nurse & 20 \\
GP & 13 \\
Obstetrics & 8 \\
Dietician & 3 \\
Other & 19 \\
Unknown & 39 \\
Total & 222 \\
\hline
\end{tabular}

\section{Access to BGM Data}

All statements relating to BGM data are very strongly supported by respondents. Having consistency and reproducibility of data is considered to be of paramount importance (99.1\%), and supporting type 1 patient's treatment decisions in real-time is strongly supported $(98.2 \%)$.

The need for patients to have real-time reports of their personal BGM data is supported by $94.5 \%$ of respondents. It has been shown that automated pattern algorithms can assist in the avoidance of hypoglycemic episodes $[8,9]$. it has been reported that $32.3 \%$ of measured hypoglycemic episodes are preceded by an observed pattern of low blood glucose [10]. Data should always support treatment decisions for people with type 1 diabetes or patients using insulin (96.8\%).

Data offer patients the insight to manage their blood glucose with confidence. Respondents strongly agree that decisions made by patients should always be supported by data $(98.2 \%)$. Access to data promotes engagement with trends and patterns within the data to inform the patient in a way that complements the role of the HCP.

\section{Patient Education}

There is evidence to show that good BGM results in better outcomes and that people should be supported and educated in the interpretation of data to achieve these better outcomes. In our survey $100 \%$ of respondents support the importance of a common understanding of how to interpret and act upon BGM data, trends, and patterns. Given the nature of diabetes, it is vital that carers are actively involved with patients, and access to real-time data is an important consideration. Diabetes impacts the whole household [11].

Among respondents, 99.5\% agree that effective BGM is a necessary component of patient education; in addition, the importance of access

Total Consensus Agreement Scores by Role

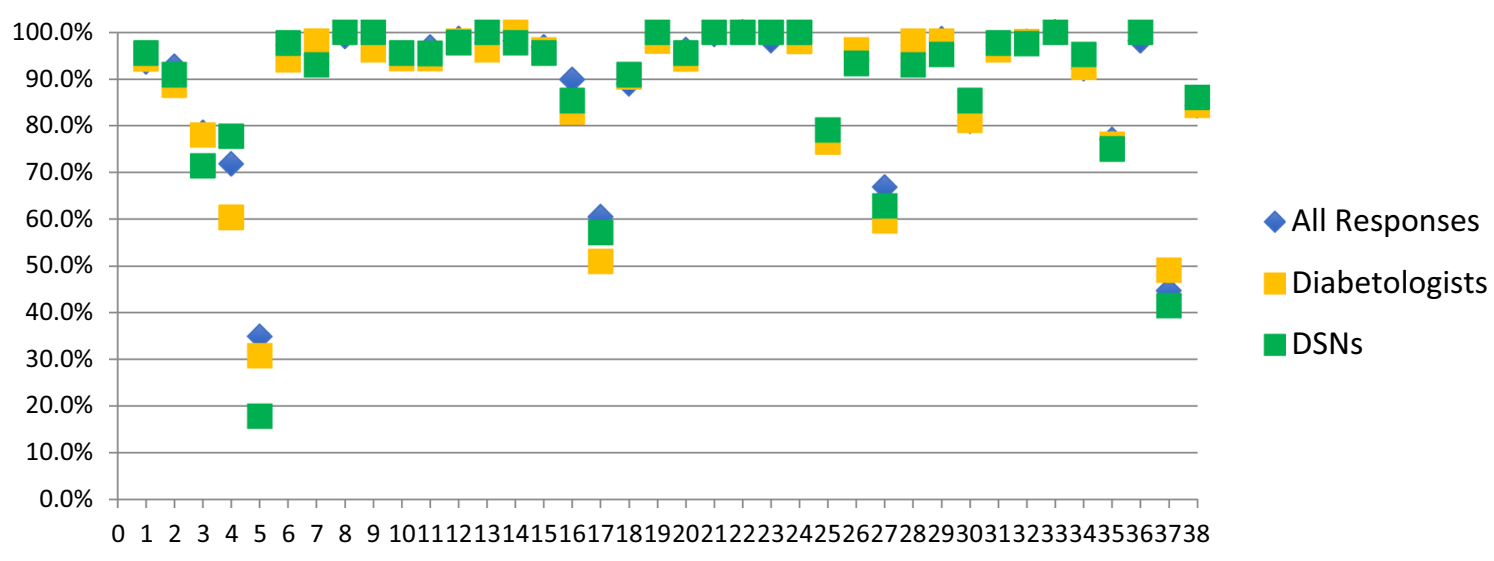

Fig. 3 Consensus agreement scores by role. DSN Diabetes specialist nurse 
Table 7 Statements with largest variation in agreement scores by role

\begin{tabular}{|c|c|c|c|c|c|}
\hline \multirow{2}{*}{$\begin{array}{l}\text { Consensus } \\
\text { statement } \\
\text { number }\end{array}$} & \multirow[t]{2}{*}{ Topic } & \multirow[t]{2}{*}{ Statement } & \multicolumn{3}{|c|}{ Agreement scores (\%) } \\
\hline & & & $\begin{array}{l}\text { Total } \\
(\%)\end{array}$ & $\begin{array}{l}\text { DSNs } \\
(\%)\end{array}$ & $\begin{array}{l}\text { Diabetologists } \\
\text { (\%) }\end{array}$ \\
\hline 3 & $\begin{array}{l}\text { Evidence } \\
\text { and } \\
\text { outcomes }\end{array}$ & $\begin{array}{l}\text { There is a lack of evidence that more expensive BGM } \\
\text { meters improve outcomes in type } 1 \text { diabetes and } \\
\text { people with diabetes using insulin }\end{array}$ & 78.5 & 71.4 & 78.0 \\
\hline 4 & & $\begin{array}{l}\text { Patient preference may be more important than } \\
\text { evidence alone in choosing an appropriate BGM } \\
\text { system in select patient groups }\end{array}$ & 71.8 & 77.8 & 60.4 \\
\hline 5 & & $\begin{array}{l}\text { HCP preference is more important than evidence } \\
\text { alone in choosing an appropriate BGM system in } \\
\text { select patient groups }\end{array}$ & 34.9 & 17.8 & 30.8 \\
\hline 17 & $\begin{array}{l}\text { Use of } \\
\text { resources }\end{array}$ & $\begin{array}{l}\text { Guidance around SMBG is misinterpreted and } \\
\text { confusing to HCPS in terms of managing patients } \\
\text { with type } 1 \text { diabetes or patients using insulin }\end{array}$ & 60.5 & 57.1 & 51.0 \\
\hline 27 & $\begin{array}{l}\text { Patient } \\
\text { education }\end{array}$ & $\begin{array}{l}\text { Resources could be saved by replacing face-to-face } \\
\text { structured education with education delivered } \\
\text { virtually using new digital/BGM solutions }\end{array}$ & 66.8 & 62.8 & 59.6 \\
\hline 30 & $\begin{array}{l}\text { Data } \\
\text { integration }\end{array}$ & $\begin{array}{l}\text { NHS data systems are not capable of sharing data } \\
\text { effectively }\end{array}$ & 81.0 & 85.4 & 81.1 \\
\hline 37 & $\begin{array}{l}\text { Patient } \\
\text { choice }\end{array}$ & $\begin{array}{l}\text { Formulary availability of BGM systems should only be } \\
\text { driven by patient choice }\end{array}$ & 44.7 & 41.5 & 49 \\
\hline
\end{tabular}

$D S N$ Diabetes specialist nurse

to BGM data and of understanding trends and patterns is strongly supported (statements 23 and 24). Access to feedback on their progress helps patients to take action to improve their diabetes control or continue with previous positive actions [2]. There is strong agreement that virtual data and applications can support education at home. Remote support in the patient's home and work environments is important so that patients are not constrained by the need to attend a clinic.

Statement 27 achieved consensus $(66.8 \%$ agreement) despite the inference that resources could be saved by replacing face-to-face education. In reality, respondents may better support the assertion that the two should complement one another. This would offer a synergistic benefit. There is $97.2 \%$ agreement among respondents that BGM offers a means to offer positive reinforcement in support of patient decisions, reflecting recent published data $[2,12]$.

\section{Data Integration}

Respondents strongly support that the notion that data systems should be integrated and inter-operable across the NHS $(97.2 \%$ agreement). Eventually, integration of data should involve a standardized approach in order to improve access and utility (statements 31 and 32). Data are of no use unless it can be effectively used and applied.

Members of the consensus group agreed that high-quality data are essential for constructive consultations; therefore, access to data will improve resource utilization and avoid wasted clinic sessions. There was $98.6 \%$ agreement 
among respondents that patients' BGM data should be accessible by every HCP involved in their care. This result is supported in the literature, with published data showing improvement in glycemic control by patients using integrated BGM data $[8,12]$. Cloud-held data may lead to better data-utility among patients and HCPs (98.1\%) as long as it is easily accessible as per regulatory guidelines. It may also facilitate remote consultations and can alleviate the problem of forgotten logbooks or devices in face-to-face consultations.

Accessible cloud-held data can also be shared/socialized with caregivers (e.g., elderly patients) and loved ones (e.g., parents of children). Studies have demonstrated improvements in outcomes when data is used in this way [8].

\section{Use of Resources}

Respondents strongly agree that manufacturers should provide quality-adjusted life-year data to support their products (89.9\%). There is a need for clear and consistent guidance regarding BGM, as evidenced by the lack of clarity from respondents regarding statement 17 .

Almost all respondents (99.1\%) agree that effective BGM will reduce the risks of hypoglycemia and ketoacidosis in patients with type 1 diabetes. New technology has the potential to improve the use of NHS resources and should be considered as an investment rather than a cost (96.3\% agreement). New technologies that facilitate effective glycemic control are strongly supported by respondents $(88.9 \%$ agreement to statement 18 , which is specific to flash glucose monitoring and $96.3 \%$ agreement to statement 20). Solutions with automated pattern algorithm integration can improve HCP efficiency and accuracy [13].

\section{Evidence and Outcomes}

Respondents strongly indicate (92.7\%) that evidence is important in improving patient care and that it should inform choices relating to BGM. Recent evidence [2] shows that switching patients to BGM systems featuring color range indicators was associated with improvements in glycated hemoglobin levels compared to subjects using a wide selection of marketed BGM systems without color support [14]. Despite this, respondents support the assertion (78.5\%) that there is a lack of evidence that more expensive BGM systems improve outcomes, suggesting that respondents may not be fully aware of recent innovations and published data. Data are available providing direct comparison between solutions that help the patient and HCP with insights and interpretation of the number versus traditional BGM [14].

While the preference of the HCP is not regarded by the respondents as being more important than evidence (34.9\%), patient preference is strongly supported $(71.8 \%)$ as more being important than evidence alone in choosing the right BGM system for the patient. Respondents strongly agree that evidence should include patient-reported outcome measures (PROMS) (97.2\%), such as real-world usability $(93.7 \%)$.

\section{Patient Choice}

A majority of respondents concurred that formulary availability should not be driven by a single factor alone, with general agreement that neither patient choice (55.3\%) nor acquisition cost $(92.2 \%)$ is sufficient to effectively make formulary choices. Interestingly, respondents are accepting of patient co-payment (77\%) as a means of accessing novel technology and supporting individualized patient choice. This is a paradigm shift and may reflect changing professional attitudes. However, many patients have traditionally self-funded their BGM regimen in the past, and the 2017 Diabetes UK Survey recently revealed that BGM is less available than patients' requirements [3].

There are $98.2 \%$ of respondents who agree that the choice of BGM system should support the achievement of the patients' own goals and $84.3 \%$ who agree that the willingness of the patient to engage with a particular BGM device should be the driving factor in choice of system. Recent data suggest that BGM supported by a web application and OneTouch Verio (OTV; 
LifeScan Inc., Milpitas, CA, USA) meter improved blood glucose control [12]. In addition, recent studies indicate that connected BGM solutions that provide access to cloudheld data allow patients to feel more secure in the knowledge that they can access their diabetes information at any time [15].

Overall, the strong support from a large respondent group underlines the need to ensure that patients have access to appropriate BGM systems in line with the needs and expectations of their health care professionals. New BGM technologies should be regarded as an investment rather than a cost, as long-term cost-effectiveness may be achieved due to a reduction in negative outcomes and admissions and in greater patient satisfaction. This opportunity reflects the wider shift towards value-based healthcare in the NHS.

\section{Limitations of Study}

The cascade circulation of the questionnaire from the group to their network of colleagues and the willingness of the 222 clinical professionals to respond spontaneously may have introduced bias; nevertheless, the statements produced a high level of clinical consensus in areas of uncertainty around BGM. The professionals who responded covered a wide range of disciplines and geographical spread within the UK, but despite this there was a great deal of agreement in their responses.

\section{CONCLUSIONS}

The conclusions drawn by the consensus group after consideration of the questionnaire responses are as follows:

- Informed patient choice should be regarded as the prime factor in the effective use of a BGM system.

- Patient co-payment should be supported where appropriate as this will allow more individualized patient care and empower self-management.

- Data integration is urgently required for BGM system access.
- Real-time BGM data should be made available to patients and provide positive reinforcement.

- Guidance should be inclusive of evidence, patient preference, and outcomes data.

- Wider factors, such as patient choice, should inform guidance rather than cost alone.

- New technology for BGM should be regarded as an investment rather than a cost.

- Structured education should be complemented by access to real-time feedback data.

- The choice of BGM system should support the achievement of the patients' own goals.

- Shared ownership of the responsibility for self-care is critical.

\section{ACKNOWLEDGEMENTS}

Funding. LifeScan U.K. Ltd provided financial support for the consensus process including article processing charges and steering group meetings but had no editorial control over the content of the publication or its conclusions. All authors had full access to all of the data in this study and take complete responsibility for the integrity of the data and accuracy of the data analysis.

Medical Writing. Medical writing support and project coordination was provided by Triducive Ltd., also funded by LifeScan UK Ltd.

Authorship. All named authors meet the International Committee of Medical Journal Editors (ICMJE) criteria for authorship for this article, take responsibility for the integrity of the work as a whole, and have given their approval for this version to be published.

Disclosures. Richard A. Chudleigh: Received speaker honorarium from Abbott. Naresh Kanumilli: Received honoraria from Pharmaceutical companies for advisory boards and talks (NN, Napp, Takeda, Sanofi, AZ, Abbott, Ascensia). Charlotte McMurray: Received honoraria from LifeScan. Douglas A. Robertson, Simon D. Gwynn, Carol Jairam, Kaushal Kansagra, Adam Lester- 
George, and Timothy C. Warren have nothing to disclose.

Compliance with Ethics Standards. This article does not contain any studies with human participants or animals performed by any of the authors. However, we thank the colleagues who responded and gave up their valuable time to complete and return their questionnaires.

Data Availability. The datasets analyzed during this study are available from the authors on reasonable request.

Open Access. This article is distributed under the terms of the Creative Commons Attribution-NonCommercial 4.0 International License (http://creativecommons.org/licenses/ by-nc/4.0/), which permits any noncommercial use, distribution, and reproduction in any medium, provided you give appropriate credit to the original author(s) and the source, provide a link to the Creative Commons license, and indicate if changes were made.

\section{REFERENCES}

1. Clarke SF, Foster JR. A history of blood glucose meters and their role in self-monitoring of diabetes mellitus. Br J Biomed Sci. 2012;69(2):83-93.

2. Grady M, Katz LB, Cameron H, Levy BL. A comprehensive evaluation of a novel color range indicator in multiple blood glucose meters demonstrates improved glucose range interpretation and awareness in subjects with type 1 and type 2 diabetes. J Diabetes Sci Technol. 2016;10(6):1324-32.

3. Testing Times: restrictions accessing test strips and meters for people with diabetes. Diabetes UK 2017. https://www.diabetes.org.uk/resources-s3/2017-08/ 1092_Testing\%20times.pdf. Accessed Feb 2019.

4. National Institute for Health and Care Excellence (NICE). Type 1 diabetes in adults: diagnosis and management. NICE guideline [NG17]. 2015. https://www.nice.org.uk/guidance/ng17/chapter/1Recommendations\#blood-glucose-management-2. Accessed Feb 2019.

5. National Institute for Health and Care Excellence (NICE). Type 2 diabetes in adults: management.
NICE guideline [NG28]. 2005. https://www.nice. org.uk/guidance/NG28. Accessed Feb 2019.

6. Dalkey N, Helmer O. An experimental application of the Delphi method to the use of experts. Manag Sci. 1963;9:458-67.

7. Diabetes UK. Diabetes UK consensus guideline for flash glucose monitoring. 2017. https://www. diabetes.org.uk/resources-s3/2017-09/1190_Flash\% 20glucose\%20monitoring\%20guideline_SB_V9\% 5B4\%5D.pdf. Accessed Feb 2019.

8. Grady M, Katz LB, Cameron H, Levy BL. Diabetes app-related text messages from health care professionals in conjunction with a new wireless glucose meter with a colour range indicator improves glycaemic control in patients with type 1 and type 2 diabetes: randomized controlled trial. JMIR Diabetes. 2017;2(2):e19.

9. Grady M, Campbell D, MacLeod K, Srinivasan A. Evaluation of a blood glucose monitoring system with automatic high- and low-pattern recognition software in insulin-using patients: pattern detection and patient-reported insights. J Diabetes Sci Technol. 2013;7(4):970-8.

10. SB Communications Group. Recognising and addressing patterns of recurrent "highs" and "lows" in people with insulin-treated diabetes: why is it important and how to go about it? Suppl J Diabetes Nurs. 2013;17:9.

11. Diabetes.co.uk. Emotional impact of diabetes on family and friends. https://www.diabetes.co.uk/emotio nal-impact-on-families.html. Accessed Jan 2019.

12. Katz LB, Dirani RG, Li G, Randoll RA, Mahoney JJ. Automated glycaemic pattern analysis can improve health care professional efficiency and accuracy. J Diabetes Sci Technol. 2013;7(1):163.

13. Katz LB, Stewart LS, Levy BL. Benefits to health care professionals and patients with diabetes of a novel blood glucose meter that provides pattern recognition and real-time automatic messaging compared to conventional paper logbooks. Int Diabetes Nurs. 2015;12(1):27-33.

14. Grady M, Katz LB, Levy BL. Use of blood glucose meters featuring color range indicators improves glycemic control in patients with diabetes in comparison to blood glucose meters without color (ACCENTS Study). J Diabetes Sci Technol. 2018;12(6):1211-9.

15. Grady M, Cameron H, Levy BL, Katz LB. Remote health consultations supported by a diabetes management web application with a new glucose meter demonstrates improved glycaemic control. J Diabetes Sci Technol. 2016;10(3):737-43. 